\title{
Effects of Cultural Conditions in Enhancing the Production of Anti-MRSA Activity of Lasiodiplodia pseudotheobromae IBRL OS-64, an Endophytic Fungus Isolated from Leaf of Ocimum sanctum L. in Submerged Fermentation System
}

\author{
M.M.J. Taufiq* (D) and I. Darah \\ Industrial Biotechnology Research Laboratory, School of Biological Sciences, Universiti Sains Malaysia, 11800 \\ Minden, Penang, Malaysia.
}

\begin{abstract}
The effects of cultural conditions on the production of anti-MRSA activity of the endophytic fungal isolate, Lasiodiplodia pseudotheobromae IBRL OS-64 isolated from the leaf of a local medicinal herb, Ocimum sanctum Linn. was studied. The highest anti-MRSA activity of $50.0 \pm 0.1 \mathrm{U} / \mathrm{mL}$ and $1.46 \pm 0.1$ $\mathrm{g} / \mathrm{L}$ of fungal growth were obtained after incorporating all the improved cultural conditions which consisted of yeast extract sucrose broth supplemented with host plant extract, with initial medium $\mathrm{pH}$ of 6,2 mycelial plugs of 4 days old seed culture, cultivation temperature of $30^{\circ} \mathrm{C}$ and cultivated for 16 days under static conditions without the presence of light. After improvement of cultural conditions, a significant increment of anti-MRSA activity of about $57.57 \%$ ( 2.4 folds) and a slight increment of fungal growth of about $\mathbf{8 . 1 5 \%}$ (1.1 folds) were obtained compared to the cultural condition before improvement. Indeed the improvement of cultural conditions greatly affected the anti-MRSA activity and growth production by L. pseudotheobromae IBRL OS-64 isolate.
\end{abstract}

Keywords: Endophytic fungus, Lasiodiplodia pseudotheobromae IBRL OS-64, Ocimum sanctum Linn, anti-MRSA activity, submerged fermentation.

*Correspondence: fiqz04@yahoo.com.sg; +6013 4158746

(Received: 06 October 2019; accepted: 19 December 2019)

Citation: M.M.J. Taufiq and I. Darah, Effects of Cultural Conditions in Enhancing the Production of Anti-MRSA Activity of Lasiodiplodia pseudotheobromae IBRL OS-64, an Endophytic Fungus Isolated from Leaf of Ocimum sanctum L. in Submerged Fermentation System, J Pure App/ Microbiol., 2019; 13(4):2517-2531. https://doi.org/10.22207/JPAM.13.4.67

(C) The Author(s) 2019. Open Access. This article is distributed under the terms of the Creative Commons Attribution 4.0 International License which permits unrestricted use, sharing, distribution, and reproduction in any medium, provided you give appropriate credit to the original author(s) and the source, provide a link to the Creative Commons license, and indicate if changes were made. 


\section{INTRODUCTION}

Endophytic fungi are ubiquitous and largely unexplored sources of novel bioactive compounds with structurally diverse secondary metabolites. They possess highly valuable bioactive compounds to human such as antibiotics and can be exploited as huge repertoire of potent biological activities (Mishra et al. 2012). Generally the secondary metabolites produced by the endophytic fungi are biosynthetically derived from primary metabolites via genetically controlled method and enzymatic catalysed reaction that lead to formation of complex compounds (natural product). The biosynthesis of the microbial metabolites is tightly control by regulatory mechanisms to avoid overproduction. These regulatory mechanisms often limit the yield of metabolites production especially through submerged fermentation system (SmF). SmF is a fermentation process that uses soluble substrate and growth medium by inoculating with microbes in shake flask or bioreactor systems. All the needed nutrients such as nitrogen and carbon sources are supplied in to this system to support microbial growth. This fermentation processes normally are done in shake flask or bioreactor whereby the $\mathrm{pH}$, temperature, agitation speed, mixing frequency are controlled (Favella-Torres et al., 1998; Ruiz-Sanchez et al., 2010). According to Vidyalakshmi et al., (2009), submerged culture has their own advantages such as easy to sterilize and controlling process. To circumvent this problem, an attempt can made to optimize the cultural and physiological conditions in order to enhance the production of secondary metabolites as well as its biomass.

Many reports have shown the effectiveness of the endophytic fungal extracts against MRSA. We have reported the potential of Lasiodiplodia pseudotheobromae IBRL OS64 , an endophytic fungus isolated from leaf of Ocimum sanctum Linn which possess anti-MRSA activity (Taufiq and Darah, 2018a; 2018b). The ethyl acetate extract of the fungus has shown significance effects on the MRSA cells and proven to have bactericidal effect. Thus, the optimization of cultural conditions such as pre-culture seed, initial medium $\mathrm{pH}$, incubation temperature, inoculum size, and agitation speed were performed in order to maximize the anti-MRSA activity and fungal growth of the isolate. The study is very important and significance since this is the first report of $L$. pseudotheobromae isolated from the leaf of $O$. sanctum Linn. and many of its characteristics are needed to be established.

\section{MATERIALS AND METHODS \\ Endophytic fungal culture and maintenance}

The endophytic fungus, $L$. pseudotheobromae IBRL OS-64 used in this study was provided by the Industrial Biotechnology Research Laboratory (IBRL), School of Biological Sciences, Universiti Sains Malaysia, Penang, Malaysia. It was isolated from the old leaf of $O$. sanctum and was cultured on potato dextrose agar (PDA) supplemented with powdered host plant $(2 \mathrm{~g} / \mathrm{L})$ and incubated at $30^{\circ} \mathrm{C}$ for 9 days before keeping it at $4^{\circ} \mathrm{C}$ prior to use. The isolate was subcultured regularly on sterile fresh PDA medium once a month to ensure its purity and viability.

\section{Test microorganism}

The culture of Methicillin-resistant Staphylococcus aureus ATCC 33591 which was also provided by the Industrial Biotechnology Research Laboratory, School of Biological Sciences, Universiti Sains Malaysia, Penang, Malaysia was grown on nutrient agar (NA) and incubated at $37^{\circ} \mathrm{C}$ for 24 hours. The inoculum was prepared by picking-up five single isolated colonies from 24 hours old culture and transferred into $5 \mathrm{~mL}$ of $0.85 \%$ sterile physiological saline $(\mathrm{w} / \mathrm{v})$. The turbidity of the bacterial suspension was adjusted to match 0.5 McFarland standards (approximately $1 \times 10^{8} \mathrm{CFU} /$ $\mathrm{mL}$ ). The isolate was subcultured on fresh NA medium once a month to ensure its purity and viability.

\section{Initial profiling of anti-MRSA activity}

The anti-MRSA activity and fungal growth profile before optimization were carried out to determine the cultivation day with highest anti-MRSA activity. One plug of the 6 days old endophytic fungus was inoculated into $250 \mathrm{~mL}$ Erlenmeyer flasks containing $100 \mathrm{~mL}$ of yeast extract sucrose (YES) broth supplemented with host plant powder (Taufiq and Darah, 2018a), initial medium $\mathrm{pH}$ was adjusted to $\mathrm{pH}$ 6.0. The flasks were then incubated at $30^{\circ} \mathrm{C}$ with 120 rpm agitation speed in dark condition. The anti- 
MRSA activity as well as the fungal growth was determined every two days interval for 30 days. All experiments were carried out in triplicates.

Optimization of different cultural conditions on the production of anti-MRSA activity and fungal growth

The optimization of physical cultural conditions of the submerged fermentation system for enhancing the production of anti-MRSA activity and fungal growth was carried out on pre-culture seed. The fragment of endophytic fungal culture was inoculated on PDA supplemented with powdered host plant $(2 \mathrm{~g} / \mathrm{L})$ and incubated at $30^{\circ} \mathrm{C}$. At $2,4,6,8,10$ and 12 days of cultivation, the periphery of the colony was punched using a $6.0 \mathrm{~mm}$ diameter of a sterile cork borer to get fungal plugs which then be used as inoculum.

The other physical parameters evaluated were the supplementation of growth medium with and without the host plant powder or extract), light intensity (presence or absence), incubation temperature $\left(25^{\circ} \mathrm{C}, 30^{\circ} \mathrm{C}, 35^{\circ} \mathrm{C}, 40^{\circ} \mathrm{C}\right.$ and $\left.45^{\circ} \mathrm{C}\right)$, pre-culture seed $(2,4,6,8,10,12$ days), number of agar plug (1, 2, 3, 4 and 5), agitation speed (static, 50, 100, 120 and $150 \mathrm{rpm}$ ) and initial medium $\mathrm{pH}$ of the culture medium $(4,5,6,7$ and 8$)$. All experiments were carried out in triplicates.

\section{Extraction process}

The fermentative broth was extracted using method described by Tong et al., (2011). The fungal biomass was separated from the broth using a sterile Whatman filter paper no.1 and the filtrate was then kept in a sterile glass container for subsequent study.

\section{Anti-MRSA determination assay}

The method described previously by Lorian (1991) with slight modifications was followed to determine the anti-MRSA activity quantitatively. An amount of $2.0 \mathrm{~mL}$ of crude extract (fermentative broth) was introduced into a clean aluminium screw cap universal bottle (Favorit) containing $7.9 \mathrm{~mL}$ of nutrient broth (NB). Then, $0.1 \mathrm{~mL}$ of 24 hour old culture of MRSA (in the form of bacterial suspension) was added in to the aluminium screw cap universal bottle (Favorit) and the total volume of the sample was $10.0 \mathrm{~mL}$. For blank, $2.0 \mathrm{~mL}$ of fermentative broth was introduced into an aluminium screw cap universal bottle (Favorit) containing $8.0 \mathrm{~mL}$ of NB. For control, $0.1 \mathrm{~mL}$ of 24 hour old culture of
MRSA (in the form of bacterial suspension) was added into the aluminium screw cap universal bottle (Favorit) containing $9.9 \mathrm{~mL}$ of NB without crude extract. The samples were then incubated at $37^{\circ} \mathrm{C}$ for 18 hours and the OD was measured at the wavelength of $560 \mathrm{~nm}$. The antibacterial activity of the extract was defined as one unit (U) of the antibacterial activity which resulted in the reduction or inhibition of the growth of MRSA (Darah et al., 2014). The experiment was done in triplicate.

\section{Determination of fungal growth}

The fungal growth was determined according to method described by Ibrahim et al., (2015) and the fungal cell dry weight was then expressed as g/L.

\section{Statistical Analysis}

One-way analysis of variance (ANOVA) and Duncan multiple range test (DMRT) with PASW (SPSS) Statistics version 12.0 were used to analyse the significant difference of the mean of experimental data. A 5\% confidence level or $\alpha=$ 0.05 were used to test all the experimental data.

\section{RESULTS}

Time course profiles of the anti-MRSA activity and fungal growth before improvement of physical parameters

The time course before the improvement of cultural conditions (yeast extract sucrose [YES] broth nourished with host plant powder, pH 6.0, one mycelial plug, incubation temperature of $37^{\circ} \mathrm{C}$ and $120 \mathrm{rpm}$ agitation speed) was studied for 30 days and the results are shown in Fig. 1. The results showed a gradual increment in the anti-MRSA activity which started from day 7 of cultivation and reached its maximal activity on day 22 of cultivation with $21.22 \pm 0.9 \mathrm{U} / \mathrm{mL}$. The anti-MRSA activity decreased slowly thereafter and achieved about $14.04 \pm 0.6 \mathrm{U} / \mathrm{mL}$ on day 30 of cultivation. The fungal growth on the other hand started earlier on day 2 of cultivation and reached its maximal growth on day 18 of cultivation with about $1.35 \pm 0.1 \mathrm{~g} / \mathrm{L}$. However, its growth was stagnant thereafter and achieved about $1.32 \pm 0.1$ $\mathrm{g} / \mathrm{L}$ on day 30 of cultivation. The significance of the study was tested using Duncan test, $p<0.05$. Thus, 22 days of cultivation period was optimal for anti-MRSA activity and retained in the next experiment. 


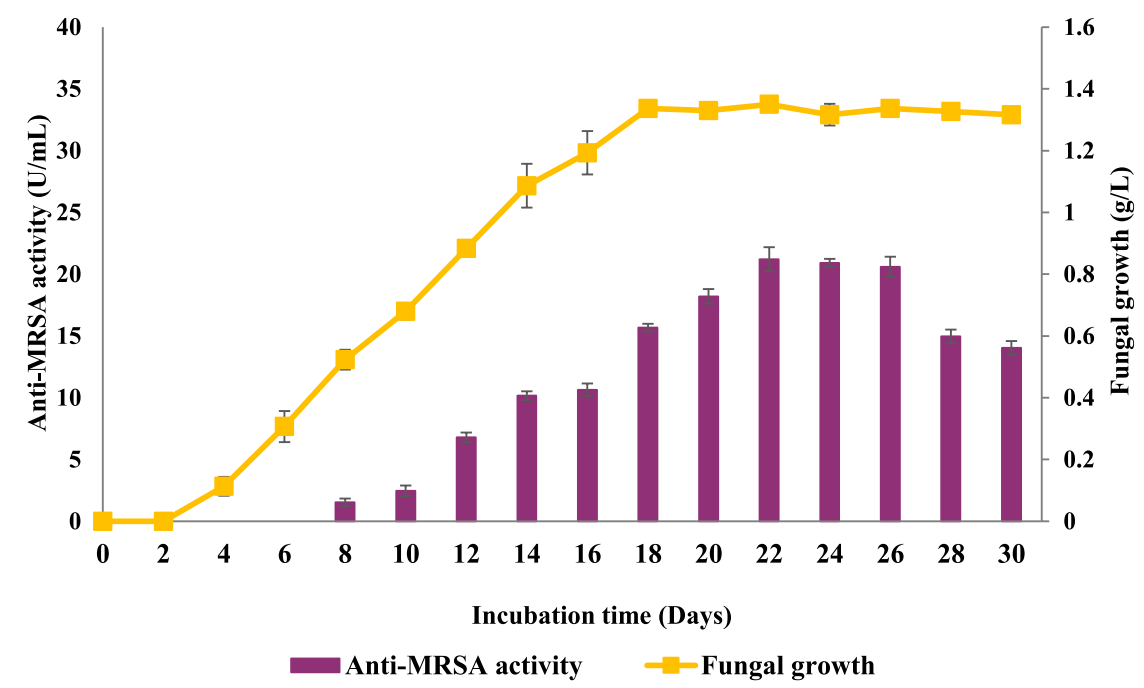

Fig. 1. Time course profile of anti-MRSA activity production and fungal growth of $L$. pseudotheobromae IBRL OS64 before improved conditions. Different letters indicate significant differences between means (Duncan, $p<0.05$ ). Standard deviation values of triplicate analyses are shown by error bars.

Improvement of cultural conditions for maximal anti-MRSA production

Effects of pre-culture seed

Six different pre-culture seeds, i.e., 2, 4, $6,8,10$ and 12 days old were tested throughout this experiment and the results are shown in Fig. 2. The 4 days old pre-culture seed produced the highest anti-MRSA activity with the value of $30.58 \pm 1.1 \mathrm{U} / \mathrm{mL}$ and the fungal growth was $1.39 \pm 0.1 \mathrm{~g} / \mathrm{L}$. Meanwhile, 10 and 12 days old preculture seed produced the least anti-MRSA activity with the value of $7.77 \pm 0.3 \mathrm{U} / \mathrm{mL}$ and $8.01 \pm 0.3$ $\mathrm{U} / \mathrm{mL}$, respectively. The anti-MRSA activity production of 2, 6 and 8 days old pre-culture seed were $22.06 \pm 0.5 \mathrm{U} / \mathrm{mL}, 15.20 \pm 0.9 \mathrm{U} / \mathrm{mL}$ and $10.00 \pm 0.2 \mathrm{U} / \mathrm{mL}$, respectively. The significance of the study was tested using Duncan test, $\mathrm{p}<0.05$. The statistical analysis revealed that 4 days old pre-culture seed was significantly promoted the highest anti-MRSA activity and was then used as a pre-culture seed for the subsequent experiment.

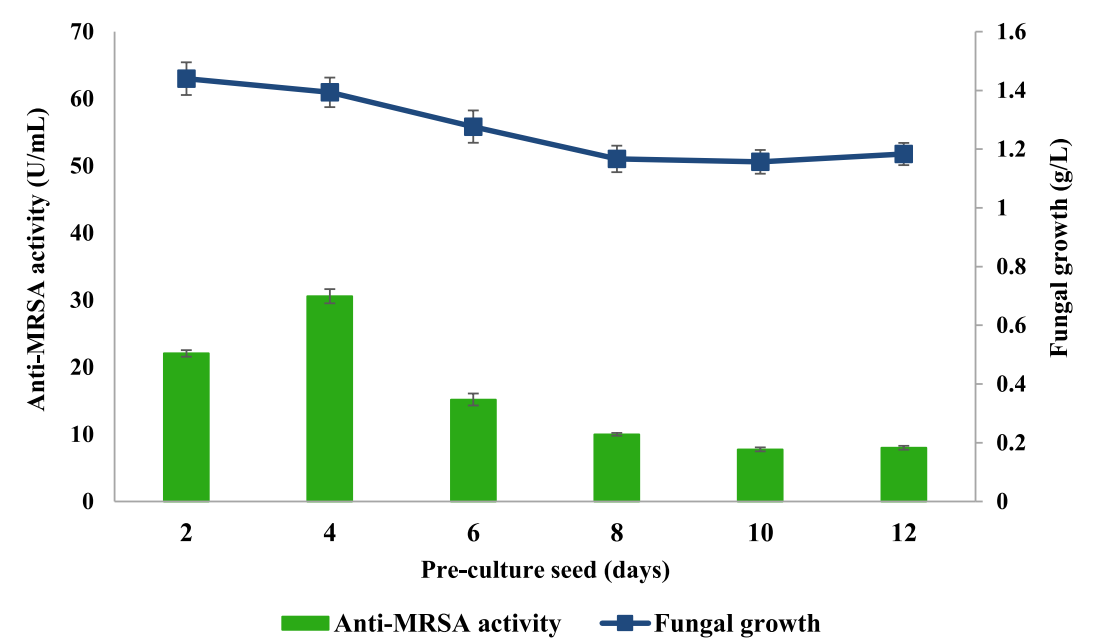

Fig. 2. Effects of pre-culture seed on production of anti-MRSA activity and fungal growth by L. pseudotheobromae IBRL OS-64. Different letters indicate significant differences between means (Duncan, $p<0.05$ ). Standard deviation values of triplicate analyses are shown by error bars. 
Effects of culture medium incorporated with or without host plant powder or extract and light intensity

The effects of culture medium incorporated with host plant, and light intensity on anti-MRSA activity was investigated and the results are shown in Fig. 3. The highest anti-MRSA activity of $38.17 \pm 0.5 \mathrm{U} / \mathrm{mL}$ was produced in the medium nourished with host plant extract and incubated in dark condition (without the presence of light). Meanwhile, the culture medium without the addition of host plant and cultivated in the presence of light produced the lowest anti-MRSA activity with the value of $22.63 \pm 1.5 \mathrm{U} / \mathrm{mL}$. The current findings revealed that the cultivation medium supplemented with host plant extract were significantly enhanced the anti-MRSA activity $(37.07 \pm 0.6 \mathrm{U} / \mathrm{mL})$ compared to the cultivation supplemented with host plant powder $(28.41 \pm 0.3$ $\mathrm{U} / \mathrm{mL}$ ). On the other hand, the cultivation medium incorporated with host plant either extracts or powder $(32.74 \pm 0.9 \mathrm{U} / \mathrm{mL})$ significantly increased the antibacterial activity compared to the medium without the addition of plant materials $(25.48 \pm 0.6$ $\mathrm{U} / \mathrm{mL}$ ). Results indicated that the endophytic fungus need its host plant material in order to enhance the anti-MRSA activity. For the effect of light intensity, the culture medium cultivated in the dark condition produced the highest anti-MRSA activity $(32.47 \pm 0.9 \mathrm{U} / \mathrm{mL})$ compared to the one that cultivated in the presence of light $(28.17 \pm 0.6$ $\mathrm{U} / \mathrm{mL}$ ). However the anti-MRSA activity production was not growth dependant. The significance of the study was tested using Duncan test, $p<0.05$. The statistical analysis revealed that the culture medium supplemented with host plant extract in dark condition showed significantly the highest anti-MRSA activity. Therefore, this condition was selected to be applied in the next experiment.

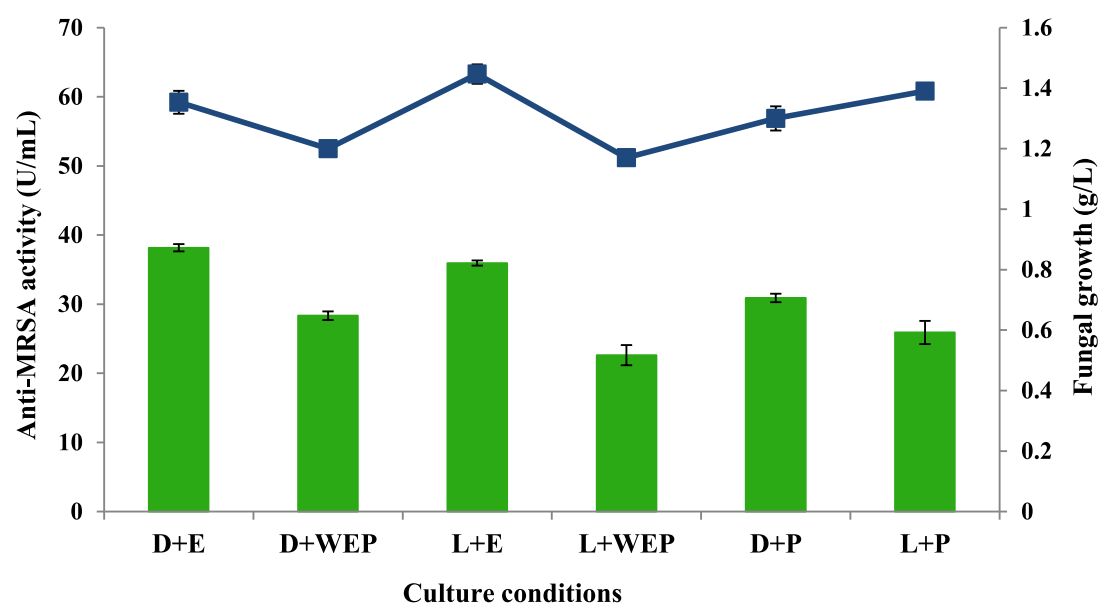

Anti-MRSA activity

$\rightarrow$ Fungal growth $(\mathrm{g} / \mathrm{L})$

Fig. 3. Effects of growth medium and light intensity on the production of anti-MRSA activity and fungal growth by $L$. pseudotheobromae IBRL OS-64. Different letters indicate significant differences between means (Duncan, $p<0.05$ ). Standard deviation values of triplicate analyses are shown by error bars. [notes: D-dark condition, WEP-without host plant extract/powder, E-host plant extract, P-host plant powder, L-in the presence of light]

\section{Effects of initial medium pH}

The effects of initial culture medium $\mathrm{pH}$ on anti-MRSA activity produced by $L$. pseudotheobromae IBRL OS-64 in a shake flask system were investigated and the results are shown in Fig. 4. The maximal production of antiMRSA activity of about $37.75 \pm 0.7 \mathrm{U} / \mathrm{mL}$ was found in $\mathrm{pH} 6$ (Duncan, $\mathrm{p}<0.05$ ). Again the anti-MRSA activity production was not growth dependant. Meanwhile, the initial medium $\mathrm{pH}$ beyond or lower than the optimal level produced lower amount of anti-MRSA activity. Thus, the initial medium $\mathrm{pH}$ of 6 was used in the subsequent studies.

\section{Effects of cultivation temperature}

The effects of various cultivation temperatures were carried out and the results are shown in Fig. 5. With the increase in cultivation temperatures, the production of anti-MRSA activity by L. pseudotheobromae IBRL OS-64 increased and reached the maximal production 
of $38.56 \pm 0.7 \mathrm{U} / \mathrm{mL}$ at the temperature of $30^{\circ} \mathrm{C}$. However, further increased in the cultivation temperature $\left(35^{\circ} \mathrm{C}\right)$ showed an abrupt declining in anti-MRSA activity. Furthermore, it is noteworthy that further increase in cultivation temperature beyond $40^{\circ} \mathrm{C}$ inhibited the fungal growth as well as the production of anti-MRSA activity. Besides that, cultivation temperatures below than $30^{\circ} \mathrm{C}$ (optimal cultivation temperature) produced lower anti-MRSA activity. Since cultivation temperature of $30^{\circ} \mathrm{C}$ produced the highest anti-MRSA activity (Duncan, $p<0.05$ ), thus, it was used in the subsequent experiment.

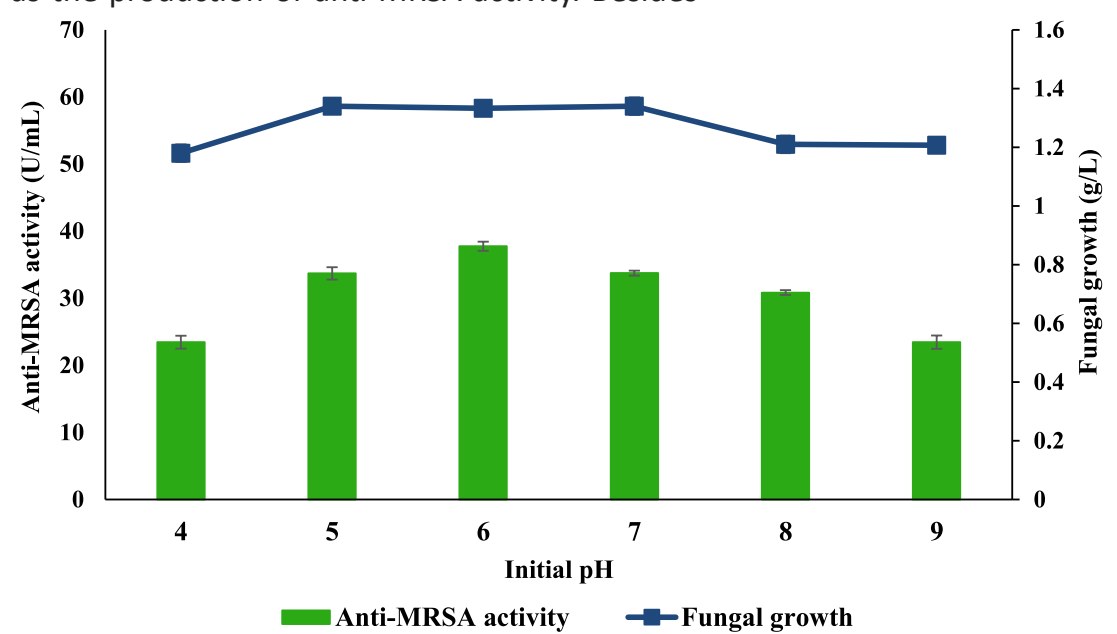

Fig. 4. Effects of initial medium $\mathrm{pH}$ on the production of anti-MRSA activity and fungal growth by L. pseudotheobromae IBRL OS-64. Different letters indicate significant differences between means (Duncan, $p<0.05$ ). Standard deviation values of triplicate analyses are shown by error bars.

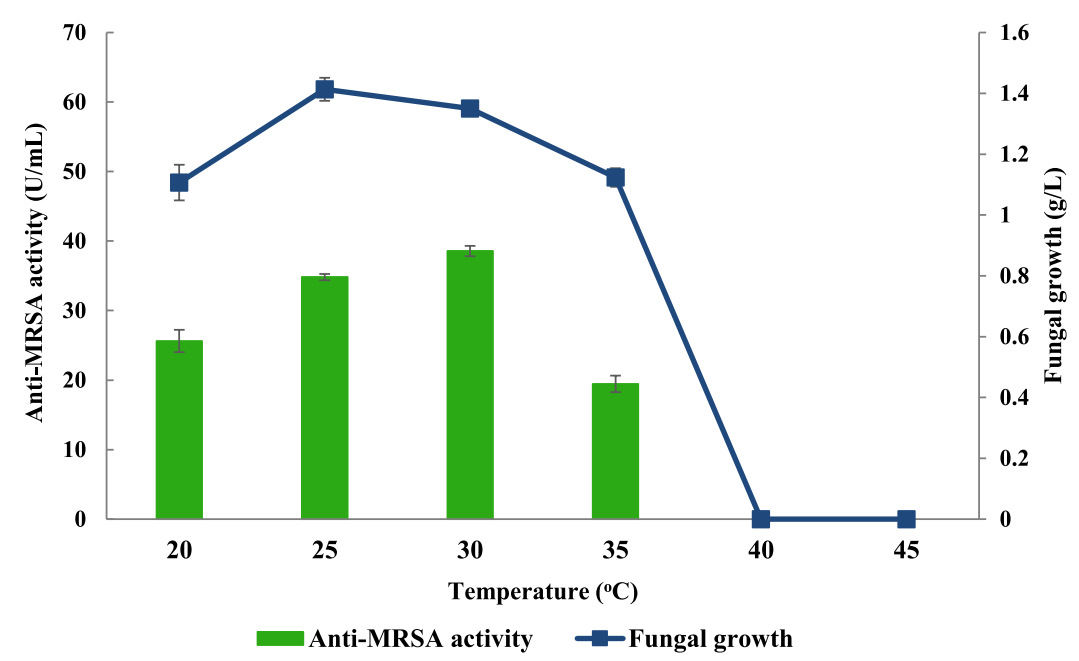

Fig. 5. Effects of temperature on the production of anti-MRSA activity and fungal growth by L. pseudotheobromae IBRL OS-64. Different letters indicate significant differences between means (Duncan, $p<0.05$ ). Standard deviation values of triplicate analyses are shown by error bars.

\section{Effects of the number of mycelial plug}

The effects of number of the mycelial plug on the production of anti-MRSA activity were studied and the results are shown in Fig. 6 . The highest anti-MRSA activity was produced by the
2 mycelial plugs of the age of 4 days old with the activity of $41.51 \pm 0.8 \mathrm{U} / \mathrm{mL}$ and the fungal growth of $1.42 \pm 0.1 \mathrm{~g} / \mathrm{L}$ (Duncan, $\mathrm{p}<0.05$ ). However, further increased in numbers of mycelial plug ( 3 , 4 and 5) gradually decreased the production of 
anti-MRSA activity as well as the fungal growth. Thus, the mycelial plug of 2 gave highest anti-MRSA activity and was then used in the next experiment. Effects of agitation speed

Agitation speed is an important condition for the fungal growth and production of antiMRSA activity in submerged fermentation. Five agitation speeds were studied and the results are tabulated in Fig. 7. The findings revealed that the static condition $(0 \mathrm{rpm})$ produced the highest anti-MRSA activity of about $47.56 \pm 0.6 \mathrm{U} / \mathrm{mL}$ and the fungal growth of $1.41 \pm 0.1 \mathrm{~g} / \mathrm{L}$ (Duncan, $\mathrm{p}<$ $0.05)$. However, the increased in agitation speeds from 50 to $150 \mathrm{rpm}$ showed a gradual decreased in anti-MRSA activity $(42.58 \pm 1.3 \mathrm{U} / \mathrm{mL}$ to $20.32 \pm 1.2$ $\mathrm{U} / \mathrm{mL}$, respectively). Since static condition showed the highest anti-MRSA activity, it was selected and retained in the next experiment.

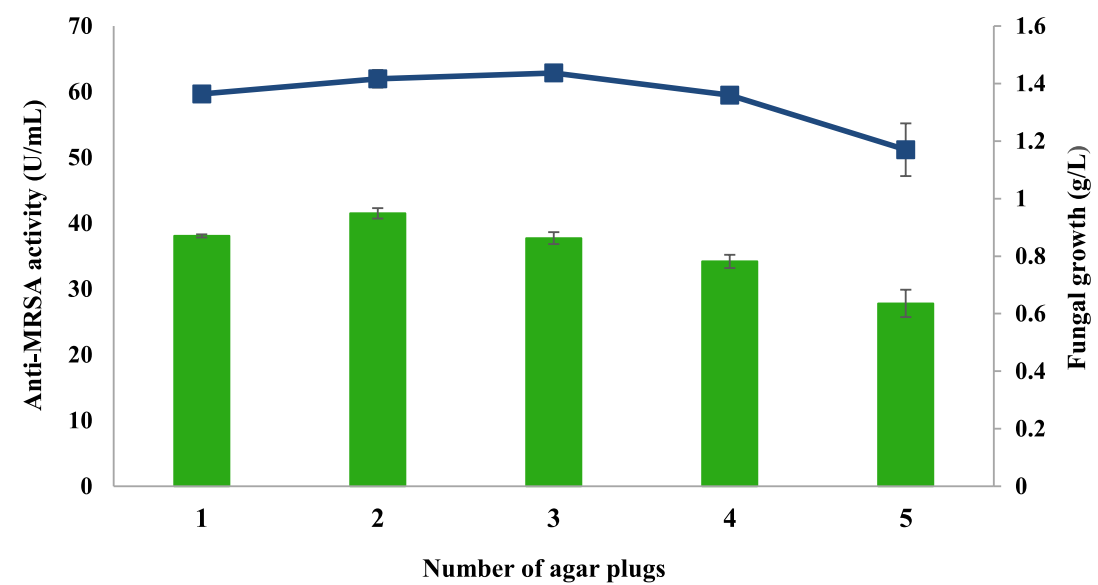

Anti-MRSA activity $\rightarrow$ Fungal growth

Fig. 6. Effects of the number of mycelial plugs on the production of anti-MRSA activity and fungal growth by $L$. pseudotheobromae IBRL OS-64. Different letters indicate significant differences between means (Duncan, $p<0.05$ ). Standard deviation values of triplicate analyses are shown by error bars.

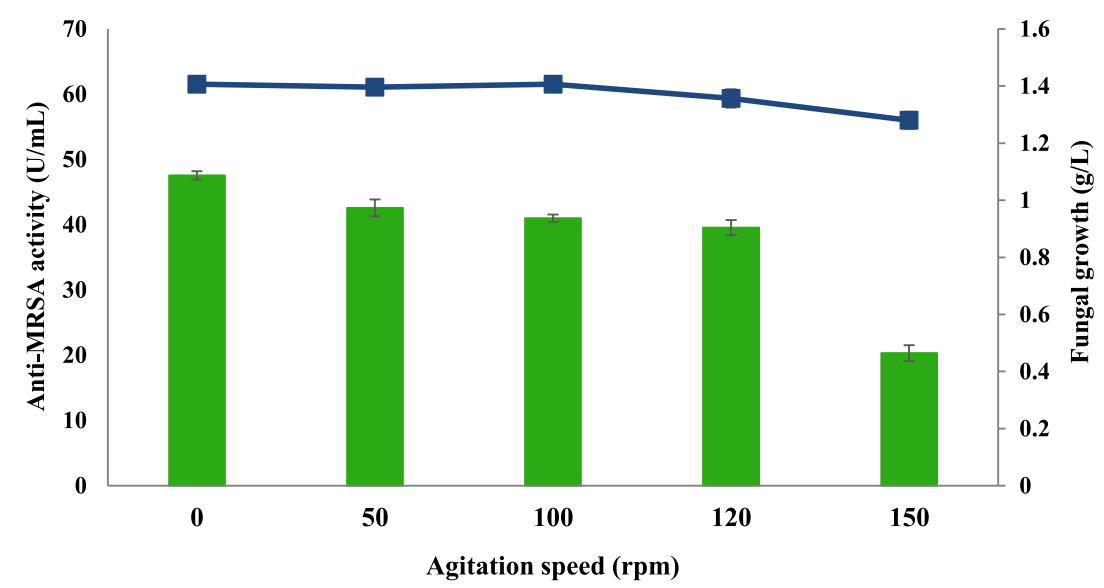

Anti-MRSA activity $\quad-$-Fungal growth

Fig. 7. Effects of agitation speeds on the production of anti-MRSA activity and fungal growth by L. pseudotheobromae IBRL OS-64. Different letters indicate significant differences between means (Duncan, $p<0.05$ ). Standard deviation values of triplicate analyses are shown by error bars.

Time course profiles after the improvement of physical parameters of submerged fermentation in a shake flask system for the production of anti-MRSA
A time course profiles for the production of anti-MRSA activity after the improvement of physical parameters were carried out and the results are shown in Fig. 8 . The profiling was 


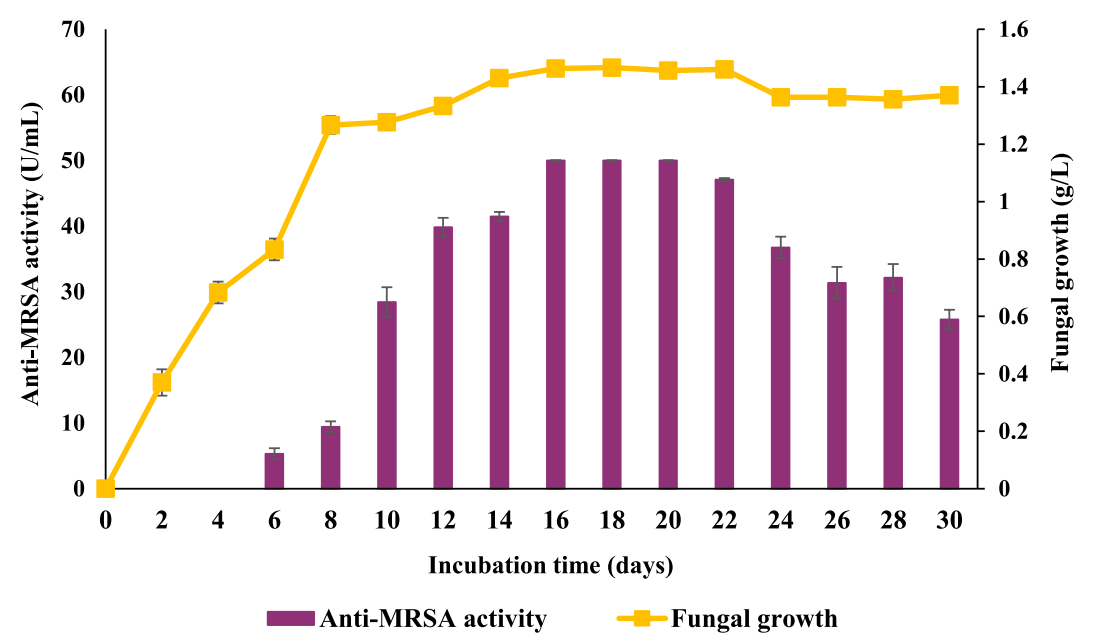

Fig. 8. Time course profiles of the anti-MRSA activity and fungal growth of $L$. pseudotheobromae IBRL OS-64 after improved conditions. Different letters indicate significant differences between means (Duncan, $\mathrm{p}<0.05)$. Standard deviation values of triplicate analyses are shown by error bars.

performed under improved culture conditions (culture medium nourished with host plant extract, initial medium $\mathrm{pH}$ of 6 , cultivation temperature of $30^{\circ} \mathrm{C}$, without the presence of light, pre-culture seed of 4 days, inoculum size of 2 mycelial plugs and under static condition) for 30 days in submerged fermentation using a shake flask system. Overall, the results showed a gradual increment in the production of anti-MRSA activity and fungal growth with the cultivation time. The anti-MRSA activity was detected as early as day 5 of cultivation and increased with the increment of cultivation time and reached its maximal production of $50.00 \pm 0.1 \mathrm{U} / \mathrm{mL}$ on the day 16 of cultivation (Duncan, $p<0.05$ ). The antiMRSA activities were stagnant on days 18 and 20 of cultivation. However, further increased in cultivation time beyond day $20^{\text {th }}$ showed a gradual decreased in anti-MRSA activity and, on day $30^{\text {th }}$, it reached the lowest activity of about $25.77 \pm 1.5 \mathrm{U} /$ $\mathrm{mL}$. In term of fungal growth, the growth started immediately after the cultivation and achieved its maximal growth of about $1.46 \pm 0.1 \mathrm{~g} / \mathrm{L}$ on day 16 of cultivation and then grow slowly until day 22 before declining thereafter. Thus, the findings of present study revealed that the improvement of physical parameters provided substantial effects on the production of anti-MRSA activity by the endophytic fungus, L. pseudotheobromae IBRL OS-64.
Table 1 summarizes the production of anti-MRSA activity as well as fungal growth before and after incorporating all the improved cultural conditions. Results revealed that the anti-MRSA activity and fungal growth increased up to $57.57 \%$ (2.4 folds) and $8.15 \%$ (1.1 folds) under improved conditions, respectively. Throughout this study, it was observed that the pre-culture seed, additional of host plant extract, number of plugs and agitation speeds played major roles in improving and enhancing fungal metabolite production. Besides that, the results also exhibited that the improvement of cultural conditions were not only enhance the production of anti-MRSA activity, but also shorten the cultivation time. Therefore, the shorter cultivation period would definitely reduce the cost for production at a commercial scale.

\section{DISCUSSION}

As far as culture conditions are concerned, there is usually a dilemma between achieving maximal fungal growth rates and maximal antibiotic yields because conditions that allow fast cell growth could be unfavourable to metabolite production (Miao et al., 2006). Furthermore in submerged fermentation there is always production of metabolites which is not dependent to the fungal growth. The yield of metabolites can sometimes be substantially increased by the improvement of physical parameters such as 
Table 1. Summary of the anti-MRSA activity and fungal growth production by L. pseudotheobromae IBRL OS-64 after improvement of physical parameters in a submerged fermentation using a shake flask system

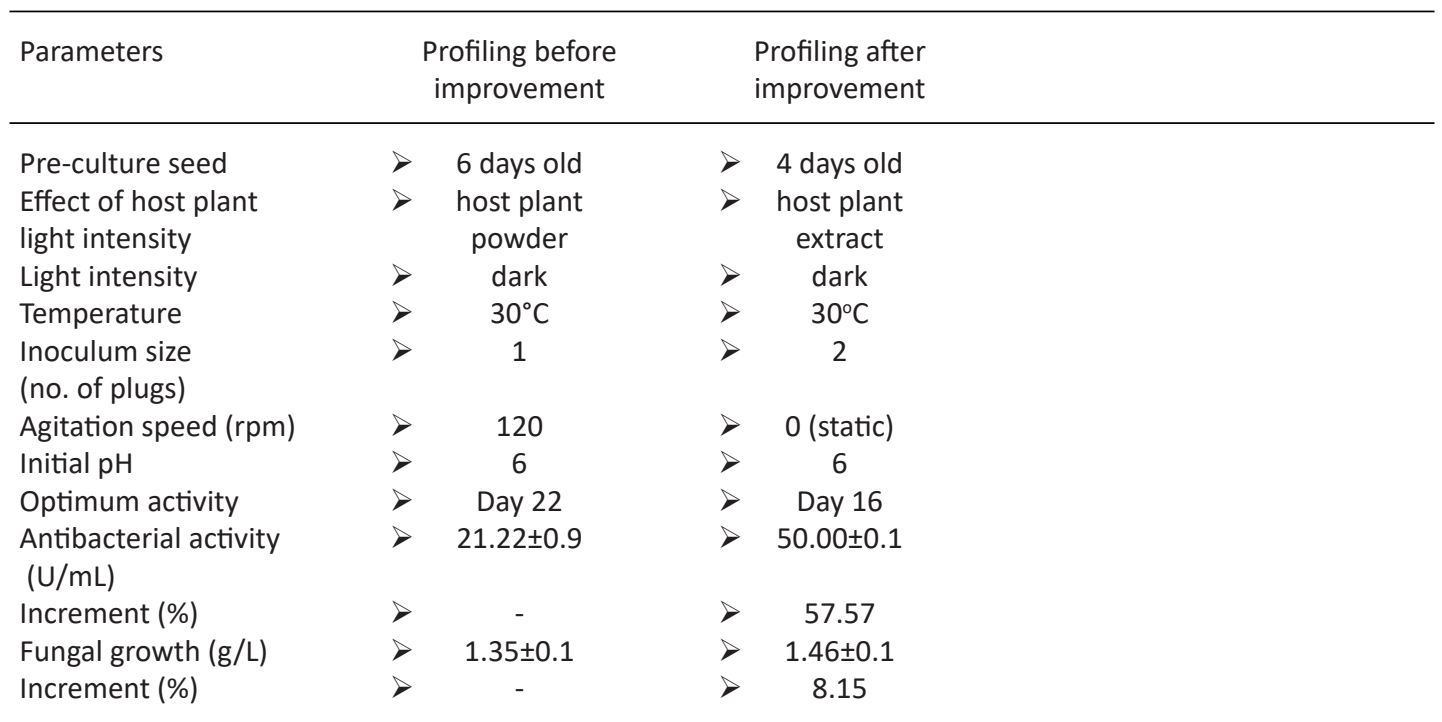

incubation temperature, initial $\mathrm{pH}$ medium value, size of inoculum, agitation speed and light (Calvo et al. 2002; Llorens et al. 2004).

The maturity of the pre-culture seed was studied to determine its effect on fungal growth and production of their secondary metabolites. The current findings revealed that younger seed culture produced the highest anti-MRSA activity as well as fungal growth. Meanwhile, older preculture seed resulted in decrement of fungal growth as well as their secondary metabolite production. This condition could be due to the old culture that was in inactive condition which needs an extent cultivation period to reproduce and re-propagate new mycelia, whereas the young active culture just continues their growth phase in a new fresh medium. Brookman et al., (2000), did a comparative evaluation on fungal growth and the results revealed that the active growth of older cultures as inoculum was delayed compared to young cultures. Similarly, Villiers (1973), reported that older seed culture might delay the germination due to repairs and replacements mechanisms in the cell that might affected organelles and enzymes. Besides that, Herker et al., (2004) reported that apoptotic regulation occurred in older microbial cells that releasing a substance into medium to stimulate the survival of new younger and fitter cells. This resulted in delayed biomass production.
Endophytes are microorganisms that symbiotically colonized within plant tissues for all or a part of their life cycle without causing any harmful effect to their host (Hirsch and Braun, 1992; Wilson, 1995). Fungal endophytes benefit and offer several advantages to their host by preventing them from desiccation, promoting plant growth hormone, increasing nutrients acquisition, protecting from insect, pathogenic fungi and environmental harsh conditions (Dutta et al., 2014; Nair and Padmavathy, 2014). Meanwhile, the host plant would provide the endophytes with shelters, space for their colonization and also nutrients acquired by them (Saikkonen et al., 2004; Schardl et al., 2004). It was observed that culture medium supplemented with host plant extract enhanced the production of fungal metabolites and their growth. The current findings were in agreement with Yenn et al., (2012) who reported the anti-candidal activity was produced by Phomopsis sp. ED32 when the culture medium was supplemented with host plant extract. Host plant extract is believed to supply the endophytes with crucial needed nutrients or growth compounds that could be used in biosynthesis of cellular components resulting in increment of fungal secondary metabolite production (Tong et al., 2011; Padhi and Tayung, 2013).

The effects of light on the secretion of fungal bioactive metabolites and their growth 
were investigated and the result showed that the presence of light slightly decreased the anti-MRSA activity of L. pseudotheobromae IBRL OS-64. Schmidt-Heydt et al., (2011) reported the same observation in which the presence of light reduced the production of ochratoxin. Similarly, Soliman and Raizada, (2018) claimed that the presence of light exhibited inhibitory effect on the production of fungal secondary metabolites. In the Taxol-producing experiment, they observed that the complete loss of taxol production occurred when the endophytic fungus SSM001 exposed to light. Kim et al., (2013a), reported the inhibitory effect of the light might be due to unavailability of LaeA nuclear protein which was a regulator protein that involved in biosynthesis of fungal metabolites and thus leads to the inactivation of secondary metabolites production. Furthermore, Kim et al., (2013b) found that white light induced the carotenoid biosynthesis by Fusarium graminearum strains. They suggested this phenomenon might be due to the role of fgWC-1 and fgWC-2 that act as negative and positive regulators, respectively that monitored the light requirement of $F$. graminearum in its biological process. Furthermore, in filamentous fungus, the light-dependent gene was expressed with the light exposure and thus, enhancing secondary metabolite production by activating the light-mediated control of the DNA expression (Wang et al., 2014). However, Velmurugan et al., (2010) stated that the fungi may react differently according to light wavelength. For instant, certain light wavelength might enhance extracellular pigment production and some are not.

The initial medium $\mathrm{pH}$ of growth medium is a crucial factor for fungal growth and production of their secondary metabolite since it affect the function of several enzymes in catabolic reaction and also influences on complex physiological phenomena such as cell morphology and their cell membrane permeability (Guimaraes et al., 2004). In the present study, the slightly acidic growth medium ( $\mathrm{pH} \mathrm{6)}$ was the best for the production of fungal secondary metabolite. The result was in agreement with previous study that reported $\mathrm{pH}$ 6 was the best for bioactive metabolite production of Streptomyces coeruleorubidus isolated from soil (Bundale et al., 2015). The current findings also revealed that production of fungal secondary metabolite of L. pseudotheobromae IBRL OS-64 was decreased with the increment of $\mathrm{pH}$ and the similar observation was reported by Keller et al., (1997). Drori et al., (2003) reported the increasing in $\mathrm{pH}$ of the growth medium from 4 to 6 was an ambient $\mathrm{pH}$ transduction pathway which increases the production of secondary metabolites by $C$. gloeosporiodes. Noaman et al., (2004) suggested the $\mathrm{pH}$ of growth medium is closely related to permeability of microbial cell wall and membrane and therefore, affected in ions uptake and loss in the growth medium. According to Rizk et al., (2007), the concentration of hydroxyl and hydrogen ion might have direct or indirect effects on the cell by varying dissociation level of substances in the medium. Thus, the change of $\mathrm{pH}$ in the medium was crucial for microbial enzyme activity especially for dissociation and solubility of intermediate products. Therefore, the extremely low and high $\mathrm{pH}$ of the growth medium is believed to disturb enzyme activity resulted in suppression of their secondary metabolite production.

Another cultural condition that has big effects on fungal secondary metabolite production is cultivation temperature (Rizk et al., 2007). In the present study, cultivation temperature of $30^{\circ} \mathrm{C}$ produced the highest anti-MRSA activity by L. pseudotheobromae IBRL OS-64. The results were in agreement with Bhattacharyya and Jha, (2011) that reported the fungal growth and their bioactive metabolite production increased with the increment of cultivation temperature from $25^{\circ} \mathrm{C}$ to $30^{\circ} \mathrm{C}$. The current finding also revealed that lower cultivation temperature resulted in slightly decrement of bioactive compounds and the temperature higher than $40^{\circ} \mathrm{C}$ killed the growth of L. pseudotheobromae IBRL OS-64. Gogoi et al., (2008) stated that a fungal endophyte, Hypocrea spp. NSF-08 which was cultivated at temperature of $28^{\circ} \mathrm{C}$ produced the highest production of bioactive metabolite, and the fungus could not grow at temperature below $20^{\circ} \mathrm{C}$ and above $50^{\circ} \mathrm{C}$. Agastian et al., (2013), stated the lower temperature might cease the fungal metabolite activity whilst at higher temperature, they might be killed.

Inoculum sizes are important in fermentation as well as secondary metabolites production by fungi. Low inoculum size may influence the time extension for cell proliferation 
to utilize substrate and produce the desired product of secondary metabolites (Darah et al., 2015). Moreover, low inoculum sizes might lead to prolongation of the lag phase of fungal growth and resulted in slow growing rate and greater fungal viability (Baert et al., 2008; Garcia et al., 2010). In the present study, this problem could be observed at inoculum size of 1 mycelial plug, where lower anti-MRSA activity was produced. On the other hand, higher inoculum size than 1 mycelial plug increased anti-MRSA activity. Thus, an inoculum size of 2 mycelial plugs was found to be optimal for the production of maximal anti-MRSA activity. The anti-MRSA activity declined slightly with further increment in inoculum sizes. Similar observation also reported by Sidhu et al., (2017) in which two mycelial discs was sufficient to stimulate higher laccase production by Scytalidium lignicola under submerged fermentation. Higher inoculum sizes than the optimal may stimulate too much production of microbial biomass which lead to nutrient depletion for their secondary metabolite production (Kumar et al., 2010). According to Ahsan et al., (2017), moderate inoculum size has a significant positive effect on the antibiotic production and growth yield. Limited space and less oxygen supply might occur if higher sizes of inoculum used in cultivation. However, if lower sizes of inoculum applied, the excess materials in the culture may turn toxic and thus lead to unfit fermentation products.

Microbial activity of aerobic cultures is markedly affected by the oxygen supply to the system. There are varying functional aspects of aeration in submerged fermentation including the maintenance of oxygen supply, removing carbon dioxide from the system and heat transfer. Aeration provides good transfer of nutrients and product gases in the submerged fermentation system. Agitation speed and dissolved oxygen are important factors in determining the successful of microbial cultivation whereby the sufficient dissolved oxygen in growth medium is crucial in mass transfer characteristics of microbial cells (Ibrahim et al., 2015). The present study revealed that the static condition produced the highest anti-MRSA activity and the activity was decreased with the increment of agitation speeds. The result obtained was in agreement with previous studies that reported the highest production of bioactive compound was obtained under static condition (Bringmann et al., 2007; Tamminen et al., 2014). The favorable effect of air flow on the secondary metabolite production could be attributed to the enhancement of product formation by microorganism under-forced aeration. The cell differentiation might be occurred under insufficient dissolved oxygen which leads to more formation of aerial hyphae and conidiophores and thus, increases the accumulation of bioactive compounds (Scott and Eaton, 2008; Tang et al., 2015). This statement was supported by Pearce, (1997) who postulated that the fungal are able to store bioactive compounds in their mycelia. According to Ahsan et al., (2017), agitation speed influenced the dissolved oxygen temperatures and oxygen availability and therefore affecting the antibiotic production. Moreover, oxygen availability is one of the crucial factors for cell growth and production of their secondary metabolites during fermentation process (Wang et al., 2010; Dou et al., 2013). Besides that, Song et al., (2012) postulated that proper ventilation should be considered during fermentation process since the culture media containing organic and inorganic compounds that lead to the decrement in dissolved oxygen level. In contrast, Noraziah and Izyani (2012) reported the agitation could increase biomass formation by supplementing more dissolved oxygen. However, the fungal growth and their fungal mycelium morphology is dependent on several factors including the growth medium, hydrodynamic in the bioreactor, fungal strains, and method of initiation of culture such as mycelium dispersion (Lopez et al., 2005). Interestingly, fungal growth of the L. pseudotheobromae IBRL OS-64 was not affected either under stationary or agitated condition since the value was almost the same even though the anti-MRSA activity was varies. According to Barborakova et al., (2012), the bioactive production is not dependent to the quantity of biomass. The agitated and static conditions of cultivation conditions might have their pros and cons, but the adaptation to the harsh environment is depends on the fungal strains and their response mechanisms to stress conditions. Even agitation is believed to provide adequate mixing especially for dissolved oxygen, heat and mass transfers, perhaps it also induce shear forces which resulted in morphological 
changes and damage of the cell structures (Darah et al., 2011; Zhu et al., 2012).

Cultivation time is also a crucial parameter in determining the success of fermentation process to gain fungal secondary metabolites. In the present study, the anti-MRSA activity was detected after about a week of cultivation time. The late detection of anti-MRSA activity might be due to the production of anti-MRSA compound as fungal secondary metabolites. According to Bu'Lock (1961), secondary metabolites are secreted during the late stage of microbial growth, at a stationary phase. It was noted in this study that the extended cultivation time $\left(22^{\text {th }}\right.$ day of cultivation time) produced maximal yield of anti-MRSA activity. The result was in agreement with Yamanaka et al., (2008) who reported the prolonged cultivation period could induce secondary metabolite production by Trametes versicolor. They also suggested that the cells are physiologically active at a long period of cultivation. Generally, the extended cultivation time would create unfavorable conditions which due to starvation of carbon or nitrogen, accumulation of self-toxic metabolites, translocation of nutrients, elevation of $\mathrm{pH}$, increment of temperature and degeneration of fungal mycelium. These unfavorable conditions are believed to adversely affect the expression of microbial secondary metabolites (Griffin, 1995). According to Sejiny (1991), during the propagation of antibiotics producers, two phases were observed which were trophophase and idiophase. Trophophase is characterized by rapid growth of microbial cells producing biomass and during the idiophase, slow microbial growth was observed and maximal antibiotic production was obtained. In the present study, all the major physical parameters which were believed to affect the fermentation process for anti-MRSA production were investigated, and the results showed that the $16^{\text {th }}$ day of cultivation time produced maximal production of anti-MRSA activity.

\section{CONCLUSION}

The present study suggests that fermentative broth of L. pseudotheobromae IBRL OS-64 exhibited a potent anti-MRSA activity through submerged fermentation in a shake flask system. The optimal cultivation conditions were significantly affected the production of anti-MRSA.
Under improved conditions, the production of anti-MRSA activity was about $50 \pm 0.1 \mathrm{U} / \mathrm{mL}$, which corresponded to $57.57 \%$ of increment compared to the yield before improvement of cultivation conditions.

\section{ACKNOWLEDGEMENTS}

The authors are grateful to Universiti Sains Malaysia and Ministry of Education, Malaysia to support this study.

\section{CONFLICTS INTEREST}

The authors declare that there is no conflic of interest.

\section{FUNDING}

This project was funded by Universiti Sains Malaysia through the RUI research grant scheme (ac: 1001/PBIOLOGI/811326).

\section{AUTHOR'S CONTRIBUTION}

MMJT performed all the experiments. ID supervised the entire work performed in her laboratory and was the principle investigator. ID and MMJT wrote, revised and approved the manuscript for publication.

\section{DATA AVAILABILITY}

All datasets obtained throughout this study are incorporated in the manuscript.

\section{ETHICS STATEMENT}

The authors declare that this article does not contain any studies with animals or human participants.

\section{REFERENCES}

1. Agastian, P., Merlin, J.N., Christudhas, I.V.S.N., Kumar, P.P., Optimization of growth and bioactive metabolite production: Fusarium solani. Asian J. Pharm. Clin. Res., 2013; 6(3): 98-103.

2. Ahsan, T., Chen, J., Wu, Y., Irfan, M., Shafi, J., Screening, identification, optimization of fermentation conditions, and extraction of secondary metabolites for the biocontrol of Rhizoctonia solani AG-3. Biotechnol Biotechnol Equip., 2017; 31(1): 91-98. https://doi.org /10.1080/13102818.2016.1259016

3. Baert, K., Devlieghere, F., Bo, L., Debevere, J., De-Meulenaer, B., The effect of inoculum size on the growth of Penicillium expansum in apples. Food Microbiol., 2008; 25: 212-217. https://doi. org/10.1016/j.fm.2007.06.002

4. Barborakova, Z., Labuda, R., Haubl, G., Tancinova, D. 
Effect of glucose concentration and growth conditions on the fungal biomass, $\mathrm{pH}$ of media and production of Fumagillin by a non-pathogenic strain Penicillium scabrosum. J. Microbiol. Biotechnol. Food Sci., 2012; 1: 466-477.

5. Bhattacharyya, P.N., Jha, D.K. Optimization of cultural conditions affecting growth and improved bioactive metabolite production by a subsurface Aspergillus strain TSF146. Int. J. Appl. Biol. Pharm., 2011; 2(4): 133-145.

6. Bringmann, G., Gulder, T.A.M., Lang, G., Schmitt, S., Stohr, R., Wiese, J., Nagel, K., Imhoff, F. Largescale biotechnological production of the antileukemic marine natural product sorbicillactone A. Mar. Drugs, 2007; 5: 23-30. https://doi.org/10.3390/md502023

7. Brookman, J.L., Ozkose, E., Rogers, S., Trinci, A.P.J., Theodorou, M.K. Identification of spores in the polycentric anaerobic gut fungi which enhance their ability to survive. FEMS Microbiol. Ecol., 2000; 31(3): 261-267. https://doi.org/10.1111/j.1574-6941.2000. tb00692.x

8. BuLock, J.D. Intermediary metabolism and antibiotic synthesis. Adv. Appl. Microbiol., 1961; 3: 293-342. https://doi.org/10.1016/S0065-2164(08)70514-8

9. Bundale, S., Begde, D., Nashikkar, N., Kadam, T., Upadhyay, A. Optimization of culture conditions for production of bioactive metabolites by Streptomyces spp. isolated from soil. Adv. Microbiol., 2015; 5: 441451. https://doi.org/10.4236/aim.2015.56045

10. Calvo, A.M., Wilson, R.A., Bok, J.W., Keller, N.P. Relationship between secondary metabolism and fungal development. Microbiol. Mol. Biol. Rev., 2002; 66: 447-459. https://doi.org/10.4236/aim.2015.56045

11. Darah, I., Jain, K., Sheh-Hong, L. Influence of culture condition on production of natural antibacterial red pigment produced by Serratia marcescens IBRL USM84. J Pure Appl Microbiol, 2014; 8(4): 2729-2737.

12. Darah, I., Sumathi, G., Jain, K., Lim, S.H. Influence of agitation speed on tannase production and morphology of Aspergillus niger FETL FT3 in submerged fermentation. Appl Biochem Biotechnol., 2011; 165: 1682-1690. https://doi.org/10.1007/s12010-0119387-8

13. Darah, I., Taufiq, M.M.J., Sheh-Hong, Lim. Pectinase production by Aspergillus niger LFP-1 using pomelo peels as substrate: An optimization study using shallow tray system. Indian J. Biotechnol., 2015; 14: 552-558.

14. Drori, N., Kramer-Haimovich, H., Rollin, J. Dinoor, A., Okon, Y., Pines, O., Prusky, D. A combination of external $\mathrm{pH}$ and nitrogen assimilation affect secretion of the virulence factor pectate lyase by $C$. gloeosporioides. Appl. Environ. Microbiol., 2003; 69: 3258-3262. https:// doi.org/10.1128/AEM.69.6.3258-3262.2003

15. Dou, Y., Xiao, J.H., Xia, X.X., Zhong, J.J. Effect of oxygen supply on biomass and helvolic acid production in submerged fermentation of Cordyceps taii. Biochem. Eng. J., 2013; 81: 73-79. https://doi.org/10.1016/j. bej.2013.10.005

16. Dutta, D., Puzari, K.C., Gogoi, R., Dutta, P. Endophytes: Exploitation as a tool in plant protection. Braz. Arch. Biol. Technol., 2014; 57(5): 621-629. https://doi. org/10.1590/S1516-8913201402043
17. Favella-Tores, E., Cordova-Lopez, J., Garcia-Rivero, M. and Gutierrez-Rojas, M. Kinetics of growth of Aspergillus niger during submerged, agar surface and solid state fermentations. Process Biochem., 1998; 33: 103-107. https://doi.org/10.1016/S00329592(97)00032-0

18. Garcia, D., Ramos, A.J., Sanchis, V., Marin, S., Modelling mould growth under suboptimal environmental conditions and inoculum size. Food Microbiol., 2010; 27: 909-917. https://doi.org/10.1016/j. fm.2010.05.015

19. Gogoi, D.K., Mazumder, S., Saikia, R., Bora, T.C. Impact of submerged culture conditions on growth and bioactive metabolite produced by endophyte Hypocrea spp. NSF-08 isolated from Dillenia indica Linn. in North-East India. J. Med. Mycol., 2015; 18(1): 1-9. https://doi.org/10.1016/j.mycmed.2007.10.006

20. Griffin, D.H. Fungal Physiology, 2nd ed.; John Wiley \& Sons, Ltd.: New York, NY. USA, 1995.

21. Guimaraes, L.M., Furlan, R.L., Garrido, L.M., Ventura, A., Padilla, G., Facciotti, M.C. Effect of $\mathrm{pH}$ on the production of the antitumor antibiotic retamycin by Streptomyces olindensis. Biotechnol. Appl. Biochem., 2004; 40: 107-111. https://doi.org/10.1042/ BA20030166

22. Herker, E., Jungwirth, H., Lehmann, K. A., Maldener, C., Frohlich, K., Wissing, S., Buttner, S., Fehrm, M., Stephan Sigrist, S., Madeo, F. Chronological aging leads to apoptosis in yeast. J Cell Biol., 2004; 164(4): 501-507. https://doi.org/10.1083/jcb.200310014

23. Hirsch, G., Braun, U. Communities of parasitic microfungi, in: Winterhoff, W. (Ed), Handbook of Vegetation Science. Kluwer Academic Publisher, 1992; 225-250. https://doi.org/10.1007/978-94-011-2414$0 \_8$

24. Ibrahim, D., Weloosamy, H., Lim, S. Effect of agitation speed on the morphology of Aspergillus niger HFD5A-1 hyphae and its pectinase production in submerged fermentation. World J. Biol. Chem., 2015; 6(3): 265271. https://doi.org/10.4331/wjbc.v6.i3.265

25. Keller, N.P., Nesbitt, C., Sarr, B., Phillips, T.D., Burow, G.B. pH regulation of sterigmatocystin and aflatoxin biosynthesis in Aspergillus spp, Phytopathol., 1997; 87: 643-648. https://doi.org/10.1094/ PHYTO.1997.87.6.643

26. Kim H.-K., Lee, S., Jo S.-M., Mccormick, S.P., Butchko, R.A.E., Proctor, R.H., Yun, S.-H. Functional roles of FgLaeA in controlling secondary metabolism, sexual development, and virulence in Fusarium graminearum. PLoS One, 2013a; 8: e68441. https:// doi.org/10.1371/journal.pone.0068441

27. Kim, H., Son, H., Lee, Y.-W. Effects of light on secondary metabolism and fungal development of Fusarium graminearum. J. Appl. Microbiol., 2013b; 116: 380-389. https://doi.org/10.1111/jam.12381

28. Kumar, R., Balaji, S., Uma, T.S., Mandal, A.B., Sehgal, P.K. Optimization of influential parameters for extracellular keratinase production by Bacillus subtilis (MTCC9102) in solid state fermentation using Horn meal - A biowaste management. Appl. Biochem. Biotechnol., 2010; 160: 30-39. https://doi.org/10.1007/s12010008-8452-4 
29. Llorens, A., Matco, R., Hinojo, M.J., Logrieco, A., Jimenez, M. Influence of the interactions among ecological variables in the characterization of Zearalenone producing isolates of Fusarium spp. Syst. Appl. Microbiol., 2004; 27: 253-260. https://doi. org/10.1078/072320204322881871

30. Lopez, J.L.C., Perez, J.A.S., Sevilla, J.M.F., Porcel, E.M.R., Chisti, Y. Pellet morphology, culture rheology and lovastatin production in cultures of Aspergillus terreus. J. Biotechnol., 2005; 116: 61-77. https://doi. org/10.1016/j.jbiotec.2004.10.005

31. Lorian, V. Antibiotics in Laboratory Medicine. Williams \& Wilkins, Baltimore, Maryland, USA, 1991; 17-48.

32. Miao, L., Kwong, T.T.N., Qian, P.Y. Effect of culture conditions on mycelial growth, antibacterial activity, and metabolite profiles of the marine-derived fungus Arthrinium c.f. saccharicola. Appl. Microbiol. Biotechnol., 2006; 72: 1063-1073. https://doi. org/10.1007/s00253-006-0376-8

33. Mishra, A., Gond, S.K., Kumar, A., Sharma, V.K., Verma, S.K., Kharwar, R.N. Sourcing of fungal endophytes: A beneficial transaction of biodiversity and bioactive natural products and plant protection and nanotechnology, in: Satyanarayana, T. (Ed.), Microorganisms in Sustainable Agriculture and Biotechnology. Springer, New York, 2012; 581-612. https://doi.org/10.1007/s00253-006-0376-8

34. Nair, D.N., Padmavathy, S. Impact of endophytic microorganisms on plants, environment and humans. The Scientific World Journal, 2014; 2014, Article ID 250693, 11 pages. https://doi. org/10.1155/2014/250693

35. Noaman, N.H., Fattah, A., Khaleafa, M. and Zaky, S.H. Factors affecting antimicrobial activity of Synechococcus leopoliensis, Microbiol. Res., 2004; 159: 395-402. https://doi.org/10.1016/j.micres.2004.09.001

36. Noraziah, A.Y., Nurul Izyani, A.M. Influence of carbon source and culture condition on arachidonic acid production by Candida krusei in submerged culture. 2nd International Conference on Chemical, Biological and Environment Sciences (ICCEBS'2012) June 30-July 1, Bali, 2012; 32-35.

37. Padhi, S., Tayung, K. Antimicrobial activity and molecular characterization of an endophytic fungus, Quambacteria sp. isolated from Ipomoea carnea. Ann. Microbiol., 2013; 63: 793-800. https://doi. org/10.1007/s13213-012-0534-4

38. Pearce, C. Biologically active fungal metabolites. Adv. Appl. Microbiol., 1997; 44: 1-80. https://doi. org/10.1016/S0065-2164(08)70459-3

39. Rizk, M., Abdel-Rahman, T., Metwally, H. Factors affecting growth and antifungal activity of some Streptomyces species against Candida albicans. J. Food Agric. Environ., 2007; 5: 446-449.

40. Ruiz-Sanchez, J., Flores-Bustamante, Z.R., Dendooven, L., Favela-Torres, E., Soca-Chafre, G., Galindez-Mayer, J. and Flores-Cotera, L.B. A comparative study of Taxol production in liquid and solid-state fermentation with Nigrospora sp. a fungus isolated from Taxus globosa. J. Appl. Microbiol., 2010; 109(6): 2144-2150. https:// doi.org/10.1111/j.1365-2672.2010.04846.x

41. Schardl, C.L., Leuchtmann, A., Spiering, M.J. Symbiosis of grasses with seedborne fungal endophytes. Ann. Rev. Plant Biol., 2004; 55: 315-340. https://doi. org/10.1146/annurev.arplant.55.031903.141735

42. Scott, B., Eaton, C.J. Role of reactive oxygen species in fungal cellular differentiations. Curr Opin Microbiol., 2008; 11: 488-493. https://doi.org/10.1146/annurev. arplant.55.031903.141735

43. Saikkonen, K., Wali, P., Helander, M., Faeth, S.H. Evolution of endophyte-plant symbioses. Trends Plant Sci., 2004; 9: 275-280. https://doi.org/10.1016/j. tplants.2004.04.005

44. Schmidt-Heydt, M., Rufer, C., Raupp, F., Bruchmann, A., Perrone, G., Geisen, R. Influence of light on food relevant fungi with emphasis on ochratoxin producing species. Int. J. Food Microbiol., 2011; 145: 229-237. https://doi.org/10.1016/j.ijfoodmicro.2010.12.022

45. Sidhu, A.K., Darade, S.B., Bhavsar, P.P., Gaikwad, V.B. and Patil, S.N. Isolation, screening and optimization for laccase production by Scytalidium lignicola pesante under submerged fermentation. Int. J. Curr. Microbiol. Appl. Sci., 2017; 6(4): 2477-2491. https:// doi.org/10.20546/ijcmas.2017.604.289

46. Soliman, S.S.M., Raizada, M.N. Darkness: a crucial factor in fungal taxol production. Front Microbiol., 2018; 9: 353. https://doi.org/10.3389/fmicb.2018.00353

47. Song, Q., Huang, Y., Yang, H. Optimization of fermentation conditions for antibiotic production by Actinomycetes YJ1 strain against Sclerotinia sclerotiorum. J. Agric. Sci., 2012; 4(7): 95-102. https:// doi.org/10.5539/jas.v4n7p95

48. Sejiny, M. Growth phases of some antibiotics producing Streptomyces and their identification. J King Abdul Aziz University: Sci., 1991; 3: 21-29. https://doi. org/10.4197/Sci.3-1.2

49. Tang, J. Qian, Z., Zhu, Li. Two-step shake-static fermentation to enhance cordycepin production by Cordyceps militaris. Chem. Eng. Trans., 2015; 46: 19-24.

50. Tamminen, A., Kramer, A., Labes, A., Wiebe, M.G. Production of scopularide $A$ in submerged culture with Scopulariopsis brevicaulis. Microb. Cell Fact., 2014; 13: 1-7. https://doi.org/10.1186/1475-2859-13-89

51. Taufiq, M.M.J., Darah, I. Fungal endophytes isolated from the leaves of a medicinal plant, Ocimum sanctum Linn and evaluation of their antimicrobial activities. Afr. J. Microbiol. Res., 2018a; 12(26): 616-622. https://doi. org/10.5897/AJMR2018.8812

52. Taufiq, M.M.J., Darah, I. Anti-MRSA of the ethyl acetate crude extract from Lasiodiplodia pseudotheobromae IBRL OS-64, an endophytic fungus isolated from leaf of Ocimum sanctum Linn. Int. J. Pharm. Pharm. Sci., 2018b; 10(8): 50-55. https://doi.org/10.22159/ ijpps.2018v10i8.26527

53. Tong, W.Y., Darah, I., Latiffah, Z. Antimicrobial activities of endophytic fungal isolates from medicinal herb Orthosiphon stamineus Benth. J Med Plant Res., 2011; 5: 831-836.

54. Velmurugan, P., Lee, Y.H., Venil, C.K., Lakshamanaperumalsamy, P., Chae, J.C., Oh, B.T. Effect of light on growth, intracellular and extracellular pigment production by five pigment-producing filamentous fungi in synthetic medium. J. Biosci. Bioeng., 2010; 109(4): 326-350. https://doi.org/10.1016/j. 


\section{jbiosc.2009.10.003}

55. Vidyalakshmi, R., Paranthaman, R. and Indhumathi, J. Amylase production on submerged fermentation by Bacillus spp. World J. Chem., 2009; 4(1): 89-91.

56. Villiers, T.A. Ageing and the longevity of seeds in field conditions, in: Heydecker, W. (Ed.), Seed Ecology. Proceeding 19th Easter School in Agricultural Science, University of Nottingham, 1973; 265.

57. Wang, Y.H., Fang, X.L., Li, Y.P., Zhang, X. Effects of constant and shifting dissolved oxygen concentration on the growth and antibiotic activity of Xenorhabdus nematophila. Bioresour. Technol., 2010; 101: 75297536. https://doi.org/10.1016/j.biortech.2010.04.070

58. Wang, W., Shi, X.Y., Wei, D.Z. Light-mediated control gene expression in filamentous fungus Trichoderma reseei. J. Microbiol. Methods, 2014; 103: 37-39. https://doi.org/10.1016/j.mimet.2014.05.017

59. Wilson, D. Endophyte - the evolution of the term, a clarification of its use and definition. Oikos, 1995; 73: 274-276. https://doi.org/10.2307/3545919

60. Yamanaka, R., Soares, C.F., Matheus, D.R., Machado, K.M.G. Lignolytic enzymes produced by Trametes villosa ccb176 under different culture conditions. Braz. J. Microbiol., 2008; 39: 78-84. https://doi. org/10.1590/S1517-83822008000100019

61. Yenn, T.W., Lee, C.C., Ibrahim, D., Zakaria, L. Enhancement of anti-candidal activity of endophytic fungus Phomopsis sp. ED2, isolated from Orthosiphon stamineus Benth, by incorporation of host plant extract in culture medium. J. Microbiol., 2012; 50: 581-585. https://doi.org/10.1007/s12275-012-2083-8

62. Zhu, H, Liu, W., Tian, B., Zhang, C. Fluid flow induced shear stress affects cell growth and total flavone production by Phellinus igniarius in stirred-tank bioreactor. Chiang Mai J. Sci., 2012; 39: 69-75. 